\title{
Saberes e práticas de enfermeiros e obstetras: cooperação e conflito na assistência ao parto
}

\author{
Cooperation and conflict in childbirth care: \\ representations and practices of nurses \\ and obstetricians
}

Antonia Angulo-Tuesta 1

Karen Giffin 1

Andréa de Sousa Gama 1,2

Eleonora d'Orsi 1

Gisele Peixoto Barbosa 1,3

\footnotetext{
1 Núcleo de Gênero e Saúde, Departamento de Ciências Sociais, Escola Nacional de Saúde Pública, Fundação Oswaldo Cruz. Rua Leopoldo Bulhões 1480, Rio de Janeiro, $R J$ 21041-210, Brasil. antoniat@uol.com.br karengi@ensp.fiocruz.br 2 Faculdade de Serviço Social, Universidade do Estado do Rio de Janeiro. Rua São Francisco Xavier 524, Bloco D,

Rio de Janeiro, $R J$ 20550-900, Brasil.

3 Programa de Assistência Integral à Saúde da Mulher, Criança e Adolescente, Secretaria de Estado de Saúde do Rio de Janeiro. Rua México 128, Rio de Janeiro, $R J$ 20031-142, Brasil.
}

\begin{abstract}
In Brazil, where birthing generally occurs in hospitals and under the care of obstetricians, the incorporation of nurses is a strategy that has been used recently in an attempt to improve obstetric care. This study, conducted in two maternity hospitals in Rio de Janeiro, focuses on representations of obstetricians and nurses regarding teamwork and analyzes how the dimensions of power, cooperation/conflict, and technical autonomy are permeated by dualistic conceptions which influence the quality of health care for women during childbirth. On the one hand, the results show a consensus regarding the advantages of professional cooperation in the improvement of health care, assuming the existence of a clear definition of professional roles. At the same time, conflicts regarding therapeutic conduct during the birth process reflect the professionals' perceptions of autonomy and the influence of professional hierarchies, in which obstetric care is seen to depend on the "objective observation" of the women giving birth. The degree of conflict is differentiated according to the institutional context and related to dualistic conceptions such as objective/subjective, rational/emotional, and male/female.
\end{abstract}

Key words Parturition; Midwifery; Obstetrics; Obstetrical Nursing

Resumo A incorporação crescente de enfermeiros constitui uma das estratégias para melhorar a assistência obstétrica no Brasil, onde o parto é atendido sobretudo por obstetras e em hospitais públicos. Nosso estudo, realizado em duas maternidades do Rio de Janeiro, busca compreender as representações de obstetras e de enfermeiras sobre o trabalho em equipe. Analisa de que forma as dimensões de poder, cooperação e conflito, e autonomia técnica são permeadas por concepções dualistas que influem na organização e qualidade da atenção à parturiente. Os resultados revelam, de um lado, o consenso sobre as vantagens da cooperação profissional para a melhoria da atenção, tendo como premissas a definição de papéis e a valorização de habilidades pessoais. De outro, conflitos vinculados às atribuições profissionais e condutas terapêticas no parto refletem a percepção dos entrevistados a respeito da autonomia e da hierarquia profissional que relacionam o cuidado obstétrico à "observação objetiva" da parturiente. A magnitude dos conflitos apresenta-se diferenciada segundo o contexto institucional, indicando ser relacionada a limitações advindas de concepções dualistas que separam objetivo/subjetivo, racional/emocional, masculino/feminino, etc.

Palavras-chave Parto; Tocologia; Obstetrícia; Enfermagem Obstétrica 


\section{Introdução}

No Brasil, a qualidade da atenção obstétrica continua a ser um ponto crítico da assistência à saúde da mulher. Apesar da melhoria dos indicadores, persistem questões preocupantes como a crescente medicalização, a utilização inadequada de tecnologias no parto e o aumento progressivo das taxas de cesáreas. Elas refletem no fato de que, nas regiões mais desenvolvidas e em mulheres com níveis de instrução mais altos, a prevalência de cesáreas é mais elevada (BEMFAM, 1997).

A fim de reverter a situação, iniciativas foram implementadas pelo setor saúde e pelas entidades de classe (CFM, 1998; COFEN, 1999), cabendo destacar o incentivo à participação dos profissionais de enfermagem-obstétrica no acompanhamento ao pré-natal e parto de gestantes de baixo risco obstétrico (MS, 2000a, 2000 b). A prática desenvolve-se sobretudo no serviço público e varia consideravelmente segundo as regiões do país. Nas regiões Norte e Nordeste, a proporção de mulheres atendidas no pré-natal ( $13 \%$ e $8 \%$, respectivamente) e no parto $(20 \%$ e $19 \%$, respectivamente) por enfermeiros, parteiras e auxiliares de enfermagem é importante quando comparada com a de outras regiões (BEMFAM, 1997). O exercício profissional de enfermagem está vinculado à prática dos obstetras, sendo o núcleo de sua atuação a gestação de baixo risco e a identificação precoce do risco.

Desde 1993, a Secretaria Municipal de Saúde do Rio de Janeiro (SMS-RJ) vem implantando a assistência de enfermagem no pré-parto e parto com outras mudanças: estímulo de práticas com o mínimo de intervenção; realização de cuidadoso acompanhamento do trabalho de parto; integração da equipe e estímulo da presença de acompanhante no pré-parto e parto. Essas visam a "oferecer à mulher a possibilidade de vivenciar com segurança e prazer este momento crucial de sua sexualidade" (Valladares, 1999:368). Em 1999, as enfermeiras obstétricas atuavam em quatro maternidades. Três atendiam gestantes de baixo risco e uma, direcionada a gestantes de alto risco.

Este artigo descreve os resultados de estudo realizado para compreender as representações dos obstetras e enfermeiras obstétricas sobre a relação interprofissional e seu impacto na qualidade da assistência obstétrica. Analisa de que forma as dimensões de poder, autonomia técnica e cooperação e conflito refletem uma ideologia dualista, expressão de uma ciência que separa, opõe e hierarquiza: ciência e arte, racional e emocional, objetivo e subjeti- vo, masculino e feminino, etc. (Santos, 2001). Enquanto esta ciência define a medicina como racional, técnica e objetiva, sua prática implica, necessariamente, relações intersubjetivas e, potencialmente, conflito. Em situações de baixo risco, onde tanto médicos como enfermeiros têm reconhecida competência técnica para agir, este potencial se manifesta mais claramente.

\section{Relações interprofissionais e trabalho em equipe}

A valorização do trabalho em equipe dos profissionais de saúde surge em decorrência de mudanças na oferta de serviços: não somente a especialização do trabalho e a crescente incorporação da tecnologia, mas também a diretriz política da atenção integral às necessidades de saúde e o reconhecimento do caráter interdisciplinar dos objetos de trabalho em saúde exigem a recomposição das ações (Schraiber et al., 1999).

Schraiber et al. (1999) distinguem dois tipos de trabalho em equipe: equipe agrupamento $\mathrm{e}$ equipe integração, esta caracterizada pela articulação das ações e resultante da intervenção ativa de cada agente envolvido na produção de cuidados. A articulação significa conectar diferentes processos de trabalho, com objetos, instrumentos e atividades próprias, e requer, da parte de cada agente, o conhecimento sobre o trabalho do outro e a aceitação da necessidade de atenção integral à saúde. A interação consistiria na busca do entendimento $\mathrm{e}$ do reconhecimento recíproco de saberes, autoridades e autonomias técnicas entre os envolvidos. Prevê a construção de consensos quanto aos objetivos e resultados a serem alcançados pelos profissionais e a maneira mais adequada de atingi-los.

Segundo Schraiber et al. (1999:233), o "trabalho em equipe é o trabalho que se compartilha, negociando-se as distintas necessidades de decisões técnicas, uma vez que seus saberes operantes particulares levam às bases distintas de julgamentos e de tomadas de decisões quanto à assistência ou cuidados a se prestar".

Esta concepção parte de dois pressupostos: (a) os trabalhos especializados expressam relações de complementaridade e interdependência entre si. Portanto, não são independentes, sendo resultado do processo de divisão de trabalho com base na prática médica. O caráter complementar não se traduz automaticamente em articulação das ações, pois é a intervenção do agente que coloca em evidência as 
conexões entre os trabalhos; (b) a complementaridade e interdependência entre os trabalhos especializados da equipe de saúde estão com freqüência em tensão com a autonomia técnica que os profissionais buscam ampliar. Autoridades técnicas diferentes passam a significar poderes e valores diferentes, e desiguais na legitimidade de julgar e decidir no trabalho, criar e recriar a técnica.

Estudos internacionais demonstram diferenças substancias na atuação de enfermeiras obstétricas, principalmente pela menor proporção de intervenções realizadas no parto. Uma das razões que explica as diferenças diz respeito ao enfoque do cuidado às gestantes, que enfatiza os aspectos educacionais e psicológicos para encorajar as mulheres no exercício de novas práticas (Oakley et al., 1995; van Wijk et al., 1996).

Pesquisas sobre relações interprofissionais entre enfermeiros, obstetras e médicos gerais de serviços de diferentes níveis de complexidade apontam divergências entre eles - inclusive no grupo de enfermeiros - quanto ao papel da enfermagem no que diz respeito às gestantes que podem atender, aos procedimentos e condutas que podem realizar, à atenção ao parto em gestantes com complicações e às circunstâncias em que devem referenciar para consulta médica (Baldwin et al., 1992; Long \& Sharp, 1982; Veer \& Meijer, 1996).

As divergências estão, sobretudo, em relação à percepção e atitude dos profissionais sobre o parto como processo fisiológico, avaliação do risco obstétrico como elemento imponderável que muda de forma precipitada a condição da mulher e o decorrer do parto, troca de conhecimentos entre profissionais para definir responsabilidades no cuidado da mulher. Elas podem provocar conflitos devido à rivalidade entre estas corporações profissionais para delimitar suas funções e atribuições (Sakala, 1993b; Veer \& Meijer, 1996).

Veer \& Meijer (1996), em estudo para determinar as possibilidades de cooperação profissional, percebem a cooperação como uma mistura de vantagens e desvantagens que podem ser conflitantes. Por exemplo, o fato de buscar melhorar a eficiência deve simultaneamente considerar o investimento de tempo necessário, o aumento de trabalho e a lentidão na tomada de decisões. Nesse sentido, existe diversidade de interesses, que torna a cooperação atividade mais complexa do que desenvolver o consenso para melhorar a qualidade da atenção obstétrica. Para os autores, a mistura de interesses reflete-se nas funções que os profissionais indicam como as mais importantes. As- sim, definem dois tipos de funções: aquelas em que os grupos têm interesses comuns, e as que têm, pelo menos parcialmente, interesses contraditórios - que persistem junto com a idéia de que a cooperação é a melhor alternativa para as partes.

\section{Gênero, ciência e assistência obstétrica}

A elevação das taxas de cesáreas, ao longo das duas últimas décadas na maioria de países, estimula a análise da relação médico-gestante e das relações institucionais da prática obstétrica. Sakala (1993a), em estudo sobre cesárea nos Estados Unidos, assinala que as principais indicações revelam a distância entre a prática médica e as evidências científicas, pois a maioria de cesáreas atribui-se a diagnósticos ambíguos e/ou na qual a conduta não oferece benefícios, ou estes são altamente questionáveis.

LoCicero (1993), analisando de que forma a relação entre obstetras e parturientes pode contribuir à manutenção de altas taxas de cesáreas e intervenções desnecessárias no préparto e parto, aponta que os processos de interação são moldados e afetados por estereótipos e relações de gênero. Esta autora nota que a estrutura intelectual ou cognitiva da obstetrícia origina-se num modelo científico/masculino: os obstetras privilegiam a "observação objetiva”, na crença de que ao se distanciar de qualquer fator pessoal e emocional, podem realizar as observações mais aprimoradas e estariam capacitados para um agir científico. Dessa forma, podem compreender, dominar e controlar os processos naturais, como o trabalho de parto e o parto. Assume-se que avaliações corretas e precisas dependem da separação de qualquer elemento emocional. Assim, "o impessoal é valorizado acima do pessoal" (LoCicero, 1993: 1263).

Segundo LoCicero (1993), chamar esse modelo de "masculino" não significa que todos os homens ou só eles pensam ou trabalham dessa forma. Está associado a eles porque os homens, mais do que as mulheres, tradicionalmente têm valorizado essa forma de pensar e atribui-se a eles com maior freqüência do que às mulheres. Assim, o cuidado obstétrico oferecido pelos médicos almeja ser objetivo e desvinculado de emoções - suas próprias e também das parturientes. A ansiedade, a tensão e o medo experimentados pelas gestantes no trabalho de parto e parto, apesar de sua comprovada interferência no progresso do parto, serão pouco valorizados pelos médicos. Ao mesmo tempo, o próprio atendimento oferecido às 
grávidas pode gerar ansiedade pelo desafeto, abandono e incompreensão de parte dos obstetras.

LoCicero (1993) chama a atenção para a questão de gênero e poder na assistência obstétrica. Independente da presença significativa de mulheres na obstetrícia, atualmente, a prática da maioria deste/as profissionais responde a padrões advindos do modelo masculino/científico de atenção. Assim, há uma expectativa de que o/a obstetra atue conforme os estereótipos masculinos (independentes, dominantes, racionais, duros, insensíveis e autoconfiantes) ao mesmo tempo em que as parturientes representem os estereótipos femininos (emotivas, charmosas, dependentes, fracas, submissas, sensíveis e gentis).

\section{Metodologia}

Esta pesquisa foi desenvolvida em duas maternidades públicas do Rio de Janeiro, no primeiro semestre de 1999. As maternidades definiram-se segundo dois critérios: nível de complexidade e tempo de implantação da assistência de enfermagem na sala de parto. Uma delas atendia gestantes de alto risco (MAR), com enfermagem atuando por mais de 10 anos (início em 1987). Outra atendia gestantes de baixo risco (MBR), com um ano de atuação de enfermagem, início em 1998 (SMS-RJ/FE-UERJ, 1998).

Realizaram-se entrevistas semi-estruturadas com 14 obstetras (7 em cada maternidade, um obstetra por plantão) e com os 21 enfermeiros da sala de parto (10 na MBR e 11 na MAR), 20 dos quais eram enfermeiras. Neste artigo utilizaremos o termo "enfermeiras" para nos referir ao conjunto deles. As entrevistas foram gravadas e realizadas nos plantões, o tempo variando entre uma hora e uma hora e quarenta minutos. $\mathrm{O}$ estudo foi aprovado pelo Comitê de Ética em Pesquisa da Escola Nacional de Saúde Pública e, em cumprimento à Resolução 196/ 96, os entrevistados assinaram o Termo de Consentimento Livre e Esclarecido.

Na MBR, os obstetras entrevistados têm idade média de 33,5 anos, variando entre 30 e 41 . Três são mulheres. O tempo médio de trabalho é de 6 anos, variando entre 1,5 e 21. As enfermeiras têm idade média de 31 anos, variando entre 25 e 50 . Um é homem. As nove enfermeiras trabalham na maternidade desde a implantação da estratégia (um ano).

Na MAR, os obstetras têm idade média de 36,8 anos, variando entre 30 e 41 . Três são mulheres. O tempo médio de trabalho na maternidade é de 7,4 anos, variando entre 5 e 13 anos.
As onze enfermeiras têm idade média de 29 anos, variando entre 24 e 34 . O tempo médio de trabalho é de 3 anos, variando entre 9 meses e 11 anos. Seis delas trabalham há um ano.

\section{Resultados}

\section{Percepção geral acerca do trabalho em equipe}

Quando perguntados sobre o trabalho em equipe, os sujeitos da pesquisa, de modo geral, expressam visões muito próximas, qualificandoo como fundamental e importante para a melhoria da assistência obstétrica. Eles concordam que para alcançar esses objetivos são necessárias condições como: (a) definição de papéis, atribuições e competências da equipe, (b) complementaridade de funções, (c) adequada capacitação e habilidades técnicas dos profissionais: "O trabalho em equipe é necessário e fundamental para uma boa assistência à saúde ... eu acho que são as pessoas realizando seus papéis profissionais mas não de forma isolada, percebendo o outro e valorizando o papel do outro" (Enfermeira - MAR). "É um trabalho em que você tem confiança nos seus colegas, para que quando você esteja fazendo outra função você saiba que as pessoas estão trabalhando com a mesma filosofia..." (Médico-obstetra MAR).

Entretanto, diferente dos discursos dos obstetras, em que prevalecem aspectos técnicos (responsabilidades e funções profissionais), as enfermeiras falam da maior valorização relacional como: (a) integração e cooperação mútua; (b) relações horizontais para facilitar a comunicação; (c) intercâmbio de experiências, conhecimentos e informações sobre as gestantes; (d) acessibilidade ao obstetra; (e) respeito e confiança na capacidade técnica dos profissionais; (f) intercâmbio de responsabilidades do cuidado e (g) atitude e disposição dos profissionais para realizar diversas tarefas.

"Você vai precisar do conselho dos outros colegas (...) vai precisar do suporte médico..." (Enfermeira-MBR).

"É você ter tranqüilidade de em algum momento ele me repassar, em algumas situações eu repassar para ele e ser uma troca constante, todo mundo trabalhando com um objetivo comum: assistir às mulheres na melhor forma possível..." (Enfermeira-MBR). 
Percepção geral das vantagens

e desvantagens do trabalho em equipe

De maneira geral, os entrevistados são enfáticos ao assinalar vantagens. Destacam: (a) melhoria da qualidade da assistência (diagnóstico adequado, acompanhamento permanente e terapêutica oportuna); (b) elevada eficiência na atenção obstétrica para diminuir riscos e complicações e (c) intercâmbio de conhecimentos e experiências.

Os obstetras ressaltam a importância de delegar funções e responsabilidades segundo a complexidade do cuidado, para privilegiar a atenção a gestantes de alto risco. As enfermeiras da MBR dizem que a principal vantagem é o uso racional de recursos com a distribuição adequada de responsabilidades. Algumas enfermeiras apontam outras vantagens: (a) complementaridade de saberes e responsabilidades; (b) confiança na capacidade profissional; (c) melhor comunicação entre profissionais; (d) incentivo ao processo de ensino e aprendizagem (discussão de casos): “A agilidade da coisa ... se você se dá bem com a sua equipe ela tende a fluir o mais certo possível, se você não se entrosa entre a equipe, aí tudo é problema..." (Enfermeira - MAR). "Sentir que a coisa está andando porque todo mundo está fazendo o seu. Quando você tem um parto bem-feito não foi só o médico que fez esse parto, mas a enfermagem cuidou dessa paciente, a rouparia colocou uma roupa limpa para ela deitar, a papeleta da paciente está bem escrita..." (Médico-obstetra-MBR).

\section{Avaliação do trabalho em equipe nos seus centros de atuação}

\section{- Maternidade de Alto Risco (MAR)}

De modo geral, as enfermeiras avaliam de forma positiva o trabalho em equipe com os obstetras e auxiliares de enfermagem. As entrevistadas, em especial aquelas autodenominadas "novas" (entre um e três anos de trabalho) ressaltam que esse resultado explica-se por três fatores: (a) confiança mútua nas habilidades e competências de obstetras e enfermeiras; (b) reconhecimento e valorização progressiva, de parte dos médicos, das responsabilidades das enfermeiras e (c) interesse e atitudes pessoais. Na avaliação das entrevistadas, a integração é decorrência do processo longo, iniciado por iniciativa da direção da maternidade, com a implantação de estratégias como a participação da enfermagem na sala de parto. Para elas, definiram-se "claramente" funções e responsabilidades de enfermeiros e obstetras. As mudanças comprometeram os profissionais a melhorar a qualidade da atenção e, principalmente, a reverter os elevados índices de asfixia perinatal. Assim mesmo, consideram que a experiência dos obstetras atuando com as enfermeiras lhes permitiu transmiti-la aos novos profissionais: "Eu acho que aqui teve o apoio de alguém que acreditou na enfermagem, e que a enfermagem não deixou a peteca cair, continua brigando, continua mostrando que é capaz" (Enfermeira - MAR). "Você precisa estabelecer uma relação de confiança, para isso você precisa conhecer o trabalho do outro e as habilidades técnicas do outro" (Enfermeira - MAR).

Apesar dessa visão geral, algumas enfermeiras percebem resistências em determinadas equipes de obstetras para atuar de forma integrada. Segundo elas, isto acontece mais por atitudes dos obstetras ("são mais fechados", "não discutem”, “não conversam”, "não se aproximam muito") do que por discordar das responsabilidades técnicas e da autonomia profissional da enfermagem.

Os obstetras coincidem com a avaliação geral das enfermeiras sobre o trabalho em equipe, caracterizando-o pelo nível adequado de coordenação, escuta e valorização da prática das enfermeiras. A maioria dos entrevistados destaca dois fatores: (a) adequada capacitação técnica e experiência das enfermeiras e (b) disposição dos médicos para coordenar e colaborar com elas. Alguns deles reconhecem que a experiência de trabalhar com as enfermeiras contribuiu de forma significativa na aceitação dessa relação: "Os fatores foram a gente aprender que, por exemplo, a enfermagem são pessoas habilitadas e capacitadas, fazem especialização em obstetrícia para acompanhar um trabalho de parto, e eu me deixar abrir para isso também..." (Médico-obstetra - MAR). “São pessoas, no geral, com uma formação técnica e experiência acima da média do que você tem no serviço público do Rio de Janeiro" (Médica-obstetraMAR).

\section{- Maternidade de Baixo Risco (MBR)}

Enfermeiras e obstetras concordam na avaliação negativa quanto ao trabalho em equipe no entanto, as explicações diferem. Para os obstetras, o trabalho em equipe caracteriza-se em relação à "equipe médica”, percebendo-o "bastante coesa” na prática cotidiana. Com respeito à interação com enfermagem, eles qualificaram-no de "bom relacionamento" e respeito mutuo. Porém, consideram deficiente a com- 
petência técnica das enfermeiras devido ao inadequado treinamento, e discordam das responsabilidades definidas pelos gestores desta maternidade. Eles acham que a responsabilidade técnica na condução do parto deve continuar sendo exclusivamente médica. As enfermeiras devem monitorar o pré-parto em algumas situações, com pouca ou nenhuma autonomia profissional, ou seja, elas teriam papel coadjuvante. Segundo os obstetras, ampliar o papel das enfermeiras na atenção obstétrica pode colocar em risco a saúde da gestante e/ou do feto.

"A questão da enfermeira obstetriz não entra muito no mérito da equipe. Para o acompanhamento do trabalho de parto é válido, mas a gente ainda não adquiriu completa confiança para eu chegar a trabalhar realmente em equipe" (Médica-obstetra-MBR).

"Eu acho que o pessoal não é capacitado (...) piada a implantação desse negócio, porque elas chegaram dentro de um projeto, onde saberiam pelo menos qual seria o papel da obstetriz; ajudar a equipe médica no acompanhamento do trabalho de parto e parto não distócico, saber detectar uma anormalidade e chamar um médico, e isso não existe..." (Médica-obstetra - MBR).

Para as enfermeiras, no entanto, a falta de trabalho em equipe ocorre pela resistência dos obstetras em compartilhar responsabilidades. Para elas, a falta de compreensão das funções ("eles não entendem que viemos para somar") e as atitudes pessoais de alguns médicos (falta de colaboração e diálogo, de tolerância, de respeito e confiança) contribuíram para gerar conflitos, dificultando a implantação dessa estratégia, em especial, quanto à aceitação de práticas menos intervencionistas.

Nesse sentido, a sensação geral das enfermeiras é de "estranhas no ninho". Ao final do primeiro ano de inserção, a avaliação é de um processo lento, difícil e bastante heterogêneo, inclusive com as auxiliares de enfermagem e enfermeiras de outros setores que, segundo elas, não entendem o novo papel na assistência à parturiente. Algumas falam de dois tipos de equipes: um, no qual os obstetras permanecem o tempo todo ao lado das parturientes e elas não podem acompanhá-las; outro, onde os obstetras estão ausentes da assistência. Para as enfermeiras, os progressos obtidos relacionam-se com a segurança no seu desempenho técnico e, em conseqüência, as atribuições são melhor percebidas pelos profissionais: "Para você tentar fazer alguma coisa você tem de estar praticamente esperando uma brecha (...) atualmente eu faço: 'Eu posso fazer o parto?'. Em algumas situações acaba tendo permissão, como se não fosse uma atribuição sua de fato, ga- rantida dentro da instituição...” (Enfermeira MBR). "No início a gente ainda tinha um pouco de insegurança devido ao fato de não estar sendo bem acolhida, pensa bem como é difícil você se propor a fazer uma coisa nova numa instituição e não ter uma boa recepção..." (Enfermeira MBR).

\section{Cuidados na atenção à parturiente}

\section{- Maternidade de Alto Risco (MAR)}

Segundo os entrevistados, não existem protocolos de atuação ao trabalho de parto e parto. Como um dos obstetras aponta: "Não tem uma rotina pré-determinada, existe um acordo informal" sobre condutas e procedimentos a serem realizados. As responsabilidades profissionais definem-se na prática cotidiana, considerando-se o risco obstétrico, a evolução do pré-parto e parto, as condições do feto, número de parturientes internadas, hospitalização de gestantes de alto risco, entre outros. Existe consenso entre os entrevistados de que as gestantes de baixo e alto riscos são monitoradas de forma coordenada entre ambos, realizandose os seguintes procedimentos: controle de sinais vitais, avaliação da dinâmica uterina, controle dos batimentos cardio-fetais, avaliação da progressão da dilatação uterina, entre outros.

Para os obstetras, a complementaridade de ações lhes permite concentrar esforços na atenção às gestantes de alto risco sem deixar de acompanhar às de baixo risco. Valorizam a competência técnica das enfermeiras para detectar alterações e/ou distócias no trabalho de parto, e confiam na comunicação delas para a tomada de decisões. De forma semelhante, as enfermeiras apontam que a identificação de distócias na condição materna e fetal e a comunicação com a equipe médica constituemse numa das principais responsabilidades. As seguintes falas ilustram esta dinâmica: “A gente vai assistir mediante o histórico, por exemplo, é hipertensa você vai fazer acompanhamento da pressão arterial e vai passando pro médico. Em relação à evolução do trabalho de parto, a enfermagem está o tempo todo, se a gente percebe alguma alteração se comunica e junto vai se tomar a conduta" (Enfermeira - MAR). "A gente não fala assim, não, 'o leito um é da enfermagem e vai ficar exclusivamente com ela'. $O$ tempo todo estamos monitorando também esse trabalho de parto. Se é uma paciente com risco maior, fica mais direcionado para a parte médica mesmo" (Médico-obstetra - MAR). 
(a) Desencontros entre saberes: negociação e conflitos

As diferenças entre obstetras e enfermeiras sobre quem decide as intervenções na atenção ao pré-parto e parto, conduzem a dinâmicas que podem gerar situações de conflito e negociação. Entretanto, a maioria dos entrevistados passa a idéia geral de que nessas dinâmicas prevalece a coordenação cordial e eficiente para oferecer bom atendimento. A maioria das enfermeiras considera que os procedimentos e condutas terapêuticas na condução do trabalho de parto em gestantes de baixo risco são decididas, geralmente, com os obstetras. Algumas delas acham que têm autonomia para definir condutas como monitorização eletrônica fetal e ruptura artificial de membranas, condutas que habitualmente são desenvolvidas pelos obstetras: "Em alguns momentos que a gente tenha necessidade de fazer alguma interferência, de entrar com ocitocina ou romper a bolsa, a gente entra e eles também não interferem na sua conduta..." (Enfermeira - MAR).

Na condução do trabalho de parto em gestantes de alto risco, elas coincidem ao afirmar que a prescrição de condutas e procedimentos é responsabilidade exclusivamente médica. No entanto, os obstetras são enfáticos ao afirmar que a prescrição no trabalho de parto em gestantes de baixo e alto riscos é definida pela equipe médica, apesar dos procedimentos serem realizados de forma conjunta: "Elas não fazem prescrições. Elas têm uma conduta mais para o parto natural. Agora, junto à interação nossa (...) eu me viro para ela e digo assim: 'vamos começar a acelerar esse parto, vamos botar um ocitocino, vamos romper a bolsa'. Coisas assim mais intervencionistas que elas não fazem mas têm uma interação e elas vão acompanhando" (Médico-obstetra - MAR).

De modo geral, os obstetras consideram que as enfermeiras desta maternidade têm capacidade técnica para assumir prescrições em gestantes de baixo risco. No entanto, a percepção dos obstetras de que o trabalho de parto e parto podem evoluir de forma tão intensa - algumas vezes de maneira drástica - levando a complicar a saúde da mulher e/ou do feto, faz com que eles prefiram assumir exclusivamente as decisões terapêuticas sem delegar atribuições: "O baixo risco em algum momento pode se converter em alto risco" (Médico-obstetra MAR).

“O que é risco obstétrico? Às vezes, chega uma multípara com 4, 5 filhos, tudo bem e na hora do parto tem uma complicação. Então, a paciente que era dita de baixo risco, pode ser uma paciente de alto risco. O risco obstétrico é muito relativo, depende do momento" (Médicaobstetra - MAR).

Alguns deles sentem que podem ser vítimas de processos litigiosos da sociedade por meio de processos administrativos ou legais, e que atuam numa atmosfera cada vez mais adversa que lhes exige proteger-se e fazer maiores esforços para evitar complicações nas parturientes atendidas: "Hoje em dia as coisas estão muito difíceis, quer dizer, qualquer coisa está gerando processo entre pacientes, familiares e hospitais e médicos, principalmente. Eu acho que esta responsabilidade sempre foi e sempre tem de ser do médico. Ele não pode deixar que esta responsabilidade fuja das mãos dele não" (Médico-obstetra - MAR).

Para alguns obstetras, as situações de conflito acontecem quando as enfermeiras fazem mais do que lhes compete ou tentam implementar práticas consideradas "novidades" e sem evidências científicas. Em geral, as falas mostram que algumas condutas consideradas de menor complexidade podem gerar maiores tensões do que as de maior complexidade. Além da atenção a gestantes com complicações, as situações de conflito citadas com maior freqüência são: (a) administração de líquidos à parturiente, (b) deambulação da gestante no trabalho de parto; (c) presença de acompanhante na sala de pré-parto e parto; (d) utilização rotineira de ocitocina no trabalho de parto; e (e) atenção de parto vertical.

A maioria de enfermeiras parece concordar que a oferta de líquidos, incentivo à deambulação da gestante, estímulo da presença do acompanhante, realização de parto vertical e suporte emocional podem trazer grandes benefícios para as parturientes. Mas elas sentem que um número importante de obstetras não apóia essas práticas, dificultando a implementação: “Um atrito na sala de parto é com relação ao acompanhante da paciente. A enfermagem faz questão de que a paciente tenha um acompanhante pra acalmá-la numa hora de tanta dor (...) A equipe médica, não posso dizer todos, mas a maior parte deles não gosta (...) Eles acham que atrapalha, que pergunta demais. Às vezes, eles acham ruim que os médicos façam toque de hora em hora na paciente, entendeu?" (Enfermeira-MAR).

"A Secretaria (de Saúde) permite acompanhante no parto, isso daí todo mundo sabe, mas nem sempre um acompanhante pode ficar no parto, às vezes ele não está preparado para assistir ao parto e a gente precisa tomar algumas atitudes mais intervencionistas, e com o acompanhante a coisa fica um tanto quanto inibida. 
Então, a gente pede para os acompanhantes saírem na hora do parto. Isso já criou um problema sério no nosso plantão porque a enfermagem bateu o pé, dizendo que era ordem da Secretaria e que tinha de ficar acompanhante. Ninguém está impedindo mas tem hora que realmente não pode ficar, vai atrapalhar. Nesse dia eu acho que houve uma inversão de autoridades" (Médica-obstetra - MAR).

Com respeito à realização do parto vertical, as seguintes falas mostram diferenças de abordagem profissional: "A princípio eles observavam e falavam: 'Está vendo, não é para ser assim, vocês estão inventando história, tem de ser o tradicional que é muito mais rápido, muito mais fácil, muito mais simples.' Sempre que há mudança de alguma ação na sala de parto, eles ficam primeiro negando tudo, querem provar que aquilo não é bom..." (Enfermeira - MAR). "Às vezes fica naquele parto com a paciente de cócoras, com bolsa íntegra, sem soro e a paciente já exaurida. Eu falo: 'gente, rompe essa bolsa, vamos botar um soro'. Aí, elas ficam assim, sai da rotina delas. Eu acho que tem umas pacientes que evoluem bem, outras não (...) Eu acho péssima aquela posição. Eu não gosto. Eu não vejo boa experiência nesse parto vertical. Horrível, aquele barrigão, você sentada naquela posição...” (Médica-obstetra - MAR).

Quanto à utilização de ocitocina para a indução e acentuação do trabalho de parto e amniotomia, a maioria delas opõe-se à utilização rotineira. Porém, ao avaliarem a necessidade de utilizá-los e os obstetras coincidirem com a indicação, elas consideram respeitada sua autonomia técnica: "Uma vez ou outra acontece que, por exemplo, chegou uma multípara que está com sete de dilatação e prescreve um soro com ocitócico. Para quê botar ocitócico? Aí a gente às vezes chega e conversa, até consegue barganhar com alguns plantões, 'vamos deixar mais uma hora e se não acontece nada a gente coloca"' (Enfermeira - MAR).

Com respeito à atenção ao parto, as enfermeiras concordam com os obstetras sobre a atenção às gestantes de baixo risco. Algumas referem que muitas vezes são acompanhadas pelos obstetras, mas não se consideram avaliadas. Percebem como cooperação, em especial diante de complicações, mas consideram que, em algumas circunstâncias, propicia um maior número de intervenções como o uso de ocitocina e a preferência pelo parto horizontal. Quanto à atenção ao parto de gestantes com complicações, as enfermeiras não coincidem entre elas nem com a equipe médica. Algumas acham que a decisão depende da evolução normal do trabalho de parto.

\section{(b) A construção de consensos}

A maioria de enfermeiras disse que diante de diferenças no diagnóstico, na indicação de procedimentos e na definição da terapêutica, prefere resolvê-las coordenando com os obstetras e encontrando consensos para a melhor atenção à gestante. Nos casos de desacordo, elas consideram que prevalece o critério médico, em especial quando se trata de prescrição medicamentosa. Algumas disseram não se sentirem com suficiente experiência para questionar a opinião dos obstetras. Entretanto, acham que eles interferem pouco nas condutas de atenção a gestantes de baixo risco. As falas seguintes ilustram a disposição de diálogo: “ $O$ que a gente tenta fazer é deixar o acompanhante no pré-parto e no parto. Quando é aquele médico que não gosta do acompanhante, a gente pede para ele se retirar na hora do parto ou pede pra ele esperar fora na hora do exame, depois ele volta, entendeu? A gente tenta conciliar. Tem médico que não liga, tem médico que gosta do acompanhante mas tem alguns que não gostam. Diferente da enfermagem que praticamente todas querem um acompanhante" (Enfermeira - MAR). “(Quando você não concorda com o uso de ocitocina?) Eu chego e questiono muito, 'olha vai colocar essa ocitocina?' Por exemplo, $3 \mathrm{~cm}$ de dilatação, bolsa íntegra, 'você não acha melhor manter com sorinho? Vamos colocar em decúbito lateral esquerdo'(...) eu acho que o profissional tem de utilizar uma certa malícia, eu brinco com ele, 'me dá uns 15 minutos, vamos ver se eu não vou conseguir', faz uma barganha, costumo dizer, você finge que está obedecendo, mas não precisa, no fundo, no fundo, não" (Enfermeira - MAR). “Às vezes indicações, não que elas indiquem cesariana, mas acham que não vai vir bem, você acaba dizendo que vai vir bem, aí não chegam a falar, mas olhares, entendeu? (...) eu não sou dona da verdade mas se chegar lá em baixo, encalacrar ao nascer, vai ser cesárea" (Médica-obstetraMAR).

\section{(c) Explicações sobre as diferenças: mais ou menos intervencionistas?}

A maioria dos entrevistados coincide ao explicar as diferenças: os médicos têm práticas "mais intervencionistas" Os obstetras consideram que devem assumir condutas e participar ativamente. Questionam os benefícios de práticas inovadoras propostas pelas enfermeiras, qualificando-as como "modismos" ou ineficientes. Os obstetras consideram que devido à experiência e formação técnica, eles possuem 
“autoridade" para estabelecer os critérios da atenção e o respeito à posição "hierárquica".

As enfermeiras se consideram "menos intervencionistas" porque esperam a evolução normal do pré-parto e parto. Referem que os médicos resistem a incorporar práticas benéficas para as mulheres. A maioria delas afirma o temor dos médicos em perder a posição hegemônica na assistência obstétrica em relação às parturientes e às enfermeiras.

\section{- Maternidade de Baixo Risco (MBR)}

De forma semelhante à MAR, os entrevistados dizem que não têm protocolos para o atendimento ao parto, apesar do projeto de atenção da enfermagem na sala de parto estabelecer responsabilidades e condutas a serem realizadas pelas enfermeiras.

Para os obstetras, as enfermeiras fazem prioritariamente o "acompanhamento básico" de gestantes de baixo risco (controle de funções vitais e dinâmica uterina). Poucos obstetras reconhecem que algumas enfermeiras, avaliadas favoravelmente na capacitação técnica, acompanham o trabalho de parto em gestantes de alto risco. Eles justificam esta participação devido à sua intensa carga de trabalho: admissão de gestantes (emergência), atenção do préparto e parto, realização de cesarianas e avaliação do puerpério.

As enfermeiras reportam que participam do monitoramento de gestantes de baixo risco, identificam distócias e/ou complicações que são comunicadas à equipe médica. Poucas enfermeiras - uma delas com formação médica referem acompanhar gestantes de alto risco, percebendo, dessa maneira, maior participação: "Você fica acompanhando, na medida em que você tem alguma dúvida você solicita o parecer do médico. Ele confirma ou ele acha que tem de intervir de outra forma. Se for alguma situação que cabe a você, ele vai te orientar..." (Enfermeira - MBR). "A gente vai acompanhando até onde a gente se sente capaz, quando eu não me sinto mais capaz eu passo para eles e aí fica sob a responsabilidade deles" (Enfermeira - MBR).

\section{(a) Desencontros entre saberes e práticas: negociação e conflitos}

As enfermeiras referem que não realizam a prescrição de condutas e procedimentos independente da evolução e prognóstico de trabalho de parto em gestantes de baixo risco. Atuam segundo a definição dos obstetras.

Alguns obstetras referem que determinados procedimentos, sob supervisão, podem ser rea- lizados por enfermeiras. Um deles avalia positivamente o desempenho delas no acompanhamento do trabalho de parto. No entanto, em geral afirmam seu poder de definição: “No meu plantão é a gente que define como atender no pré-parto, quando colocar a paciente na banheira, quando a paciente precisa de que fique do lado" (Médica-obstetra - MBR). "No meu plantão, em geral, não dividimos nada, não deixamos elas fazerem partos, assumimos todas as responsabilidades, elas não têm espaço para a área técnica obstétrica porque a medicina evoluiu e não há espaço para perdas ou insucessos, eu nunca perdi um feto no serviço público" (Médico-obstetra-MBR).

Quanto à atenção ao parto, poucas enfermeiras relatam ter tido esta experiência em situações de "muito baixo risco" e com supervisão médica. Devido às características do trabalho atual, a maioria delas avalia que tem escassa autonomia técnica. A indicação de procedimentos, a prescrição de condutas e a atenção ao parto em gestantes de baixo risco são práticas pouco desenvolvidas por elas. Embora as enfermeiras relatem experiências de cooperação com a equipe médica, consideram que na prática existem mais situações de conflitos. Uma das situações citadas com maior freqüência é a definição do responsável pela assistência ao parto. Para algumas delas, este momento é grandemente valorizado pelos obstetras, pois podem demonstrar experiência e capacidade técnica para realizar manobras: "Ouvi dizer que num plantão, um médico estava fazendo um parto e tinha uma obstetriz querendo fazer outro e avisou que ia fazer esse parto. Ele disse que ela não poderia fazer e deixou a paciente que ele acabou de atender sem suturar, veio fazer esse outro parto aqui. Eu achei essa o máximo!" (Enfermeira - MBR). "Eles tentam sempre mostrar pra gente que a gente não pode tudo. Vou dar um exemplo, tem médico que faz questão de fazer uma episiotomia mediana para mostrar: 'Eu posso fazer, você não'. Porque sendo a mais fisiológica não é usada? Porque pode ter uma lesão de reto. A gente nunca vai fazer, porque se tiver uma lesão de reto eu não sei suturar..." (Enfermeira-MBR).

Algumas enfermeiras acreditam que há obstetras discordando da estratégia por medo de "perder seu espaço tradicional" na atenção obstétrica. Para elas, os conflitos refletem o questionamento dos obstetras sobre aspectos importantes do trabalho em equipe: poder, hierarquia, autonomia técnica e responsabilidades na sala de parto. Dessa forma, as enfermeiras preferem evitar situações de conflito porque avaliam que não têm experiência suficien- 
te para enfrentar o embate técnico: "O que gerou muita competição no início é aquela questão de 'eu sou o médico e você é a enfermeira, você não pode exercer as funções que eu exerço..." (Enfermeira - MBR). "Existem indicações de cesárea mais seguras, se você entrar numa de questionar a indicação de um médico, eu acho que a gente não está nessa fase, eu acho que pode dizer:' mas não dá pra esperar para ver se dilata mais, se desce mais?'. (...) Nunca questionar: 'vai indicar cesárea, mas não precisa'. Eles odeiam isso(...) jogam pesado em cima" (Enfermeira MBR).

Alguns obstetras não reconhecem conflitos, porque consideram que "o papel do médico é muito bem definido”. Um deles assinala como motivo de tensão o fato dos obstetras não aceitarem a presença das enfermeiras na sala de parto. Outros assinalam que a atitude dos obstetras ao querer demonstrar maior conhecimento e prática gera conflitos: "É a questão do orgulho do saber, orgulho do conhecimento, às vezes por essa formação da pessoa envolvida com suas vaidades, querendo se colocar como sendo a pessoa que mais sabe (...)" (Médicoobstetra - MBR). "Eu acho que é mais por essa história das pessoas não conhecerem os limites. Assim como tem auxiliar que trabalha há 30 anos na admissão, que vê você novinho e acha que sabe mais do que você, às vezes existe o enfermeiro que não conhece o limite dele. Tem uma menina aqui que eu sei que ela sabe fazer parto direitinho, mas ela não sabe o limite dela. Eu tenho implicância com ela..." (Médica-obstetra-MBR).

\section{Discussão}

O objetivo central deste estudo foi analisar as representações do trabalho em equipe de enfermeiras e obstetras na atenção ao parto, visando a conhecer as dimensões desta prática, moldadas por negociações e conflitos. Os entrevistados consideram o trabalho em equipe altamente benéfico para a melhoria da atenção obstétrica. Enfatiza-se a importância da definição de atribuições e competências, a complementaridade de funções e a adequada capacitação técnica. As enfermeiras destacam o reconhecimento do trabalho recíproco, a valorização de atitudes e habilidades pessoais e a disposição para a comunicação como elementos importantes da articulação profissional. Com respeito às vantagens e desvantagens, percebe-se a possibilidade de serem conflitantes. Resultados semelhantes foram descritos em outros estudos. Por exemplo, o fato de buscar melhorar a atenção obstétrica deve considerar a maior demanda de tempo, aumento de responsabilidades e relativização da autonomia técnica. Assim também, a coordenação de responsabilidades e a conciliação de pareceres devem ter como premissa o reconhecimento do trabalho da enfermagem e a confiança recíproca na capacidade técnica.

Nossos resultados revelam que diferenças nas percepções e práticas profissionais geram situações de conflito, expressando mistura de interesses que tornam a cooperação uma atividade complexa. Os interesses podem ser comuns: ambos profissionais, por exemplo, demonstram preocupação em comunicar-se de forma fluida para avaliar adequadamente as parturientes. As enfermeiras desejam intercambiar pareceres sobre as condutas e os obstetras apreciam a comunicação delas diante de qualquer intercorrência.

No entanto, todos os profissionais gostariam de oferecer melhor atendimento às mulheres, mas existem interesses contraditórios que resultam de enfoques diferentes sobre o processo do parto e a utilização de procedimentos, levando a intervenções desnecessárias que podem causar sérias complicações à saúde da mãe e do bebê. De modo geral, as enfermeiras vêem o parto como processo fisiológico que pode ser realizado com pouca ou nenhuma intervenção, onde o bem-estar geral das parturientes e suas próprias percepções e emoções são importantes, e devem ser levadas em conta. Os obstetras consideram-no processo a ser acompanhado com medições técnicas específicas e exatas, que demanda intervenções a fim de modificar o curso de trabalho do parto e manter o controle sobre a mulher e o nascimento para evitar riscos e complicações. Nesse sentido, algumas práticas como a deambulação da parturiente, a presença do acompanhante, a restrição do uso rotineiro de ocitocina e episiotomia e o estímulo ao parto vertical provocam conflitos entre os profissionais. Não existe consenso, portanto, sobre os benefícios às mulheres, apesar da eficácia longamente demonstrada dessas práticas e da política recente que as apóia.

Na MAR, as situações não são vistas como tão críticas nem representam obstáculos ao desempenho das enfermeiras - apesar de atender gestantes de alto risco, que freqüentemente precisam de maiores intervenções médicas. Aspectos fortemente valorizados na busca de entendimento e na construção de consenso são o reconhecimento da trajetória e competência técnica das enfermeiras, a experiência de trabalho coordenado e a autonomia profissional. 
Nesse contexto, as tensões continuam, mas são melhor manejáveis.

$\mathrm{Na} \mathrm{MBR}$, as tensões profissionais tornam a atuação das enfermeiras bastante discreta em relação à proposta inicial: favorecer uma prática com menos intervenções e a participação ativa da parturiente. O discurso do saber técnico enfatiza a autoridade e a autonomia profissional, expressa na preocupação dos obstetras sobre a qualidade do cuidado e da prática dita moderna que "não aceita perdas fetais". Há uma falta de consenso sobre responsabilidades e atribuições das enfermeiras e pouco reconhecimento, pelos obstetras, da sua competência técnica. Esses aspectos geram condições de vulnerabilidade diante da implementação da estratégia, sobretudo, pela pouca experiência adquirida, dificultando as possibilidades de uma atenção menos intervencionista.

\section{Conclusões}

Os resultados deste estudo revelam que as tensões e conflitos não necessariamente aumentam com o maior risco obstétrico nem com a maior complexidade das condutas no parto. Ao contrário, os conflitos parecem ser maiores onde os riscos são, em princípio, menores: na MBR, é referente a condutas menos intervencionistas. Na MAR, a competência técnica intervencionista dos obstetras (sua "ciência objetiva”) seria em princípio balizada pela natureza da clientela (de alto risco), e sua área de competência melhor delimitada. Na MBR, a delimitação das competências é em princípio menos clara e a possibilidade de conflito maior. Nas duas maternidades, obstetras e enfermeiras concordam na utilização das práticas mais intervencionistas em situações de risco, apesar de que as enfermeiras reconhecem "negociar" para não aplicá-las nos casos que consideram desnecessários. Em contraste, a presença de acompanhante na sala de pré-parto e parto, e o incentivo para a deambulação da parturiente podem gerar situações de maior conflito do que o uso da ocitocina e amniotomia para a acentuação do trabalho de parto. As primeiras práticas citadas, em geral são promovidas pelas enfermeiras, e os obstetras, embora reconheçam que podem trazer benefícios para as mulheres, resistem em aplicá-las.

Os conflitos em torno à definição das condutas e responsabilidades profissionais refletem a importância dada à participação da parturiente no parto e ao apoio emocional oferecido a ela. De modo geral, as enfermeiras valorizam esses aspectos e favorecem práticas que respondem às necessidades "subjetivas” das parturientes, em consonância com sua visão do parto como parte de um processo fisiológico no qual as percepções e emoções da própria parturiente têm importância. A maioria dos obstetras, por outro lado, continua a valorizar a "observação objetiva" acima das questões emocionais e pessoais das mulheres (LoCicero, 1993). Estas diferenças provocam, em muitas circunstâncias, tensões entre profissionais com impacto possível na segurança e bemestar da mulher. Porém, na MAR criam-se condições para melhorar a cooperação, repercutindo de forma positiva na relação com as mulheres, em especial no reconhecimento delas como protagonistas de suas próprias experiências, com base nas suas necessidades sentidas de líquidos, acompanhante, deambulação, entre outros.

As possibilidades de construção do trabalho em equipe na atenção obstétrica dependem do aprimoramento da capacitação técnica das enfermeiras para fortalecer a autonomia profissional. Dessa forma, conseguem o reconhecimento dos saberes e práticas, como demonstra a experiência da MAR. Os resultados sugerem, além disso, a necessidade de discutir o dualismo no modelo médico, já colocado pela "crise da razão" em âmbito das ciências em geral (Santos, 2001). Assim, as tensões e os conflitos inerentes ao trabalho em equipe, inclusive em serviços com longa trajetória de inter-relação, podem ser superados e influenciar positivamente no conjunto da prática obstétrica em que se respeitem os desejos das mulheres. 


\section{Agradecimentos}

Agradecemos o apoio do Conselho Nacional de Desenvolvimento Científico e Tecnológico (CNPq) e da Fundação Ford.

\section{Referências}

BALDWIN, L.-M.; HUTCHINSON, H. L. \& ROSENBLATT, R. A., 1992. Professional relationships between midwives and physicians: Collaboration or conflict? American Journal of Public Health, 82: 262-264.

BEMFAM (Sociedade Civil Bem-Estar Familiar no Brasil), 1997. Pesquisa Nacional sobre Demografia e Saúde 1996. Rio de Janeiro: BEMFAM.

CFM (Conselho Federal de Medicina), 1998. Campanha de Promoção de Parto Normal. Rio de Janeiro: CFM.

COFEN (Conselho Federal de Enfermagem). 1999. Resolução Cofen 223. Dispõe sobre a Atuação de Enfermeiros na Assistência à Mulher no Ciclo Gravídico Puerperal. Rio de Janeiro: COFEN.

LOCICERO, A. K., 1993. Explaining excessive rates of cesareans and other childbirth interventions: Contributions from contemporary theories of gender and psychosocial development. Social Science and Medicine, 37:1261-1269.

LONG, W. N. \& SHARP, E. S., 1982. Relationships between professions: From the viewpoint of the physician and nurse-midwife in a tertiary center. Journal of Nurse-Midwifery, 127:14-24.

MS (Ministério da Saúde). 2000a. Portaria no 569/ GM, 1 de junho de 2000. Institui o Programa de Humanização no Pré-natal e Nascimento e Implantação de Centrais de Regulação Obstétrica e Neonatal. Brasília: MS.

MS (Ministério da Saúde). 2000b. Comitê de Especialistas em Enfermagem Obstétrica para Elaborar Critérios do Curso de Especialização de Enfermagem Obstétrica. Brasília: Área Técnica de Saúde da Mulher, Secretaria de Política de Saúde, MS. (mimeo.)

OAKLEY, D.; MURTLAND, T.; MAYES, F.; HAYASHI, R.; PETERSEN, B.; RORIE, C. \& ANDERSEN, F., 1995. Processes of care. Comparisons of certified nursemidwives and obstetricians. Journal of NurseMidwifery, 40:399-409.
SAKALA, C., 1993a. Medically unnecessary cesarean section births: Introduction to a symposium. Social Science and Medicine, 37:1177-1198.

SAKALA, C., 1993b. Midwifery care and out-of-hospital birth settings: How do they reduce unnecessary cesarean section births? Social Science and Medicine, 37:1233-1250.

SANTOS, B. S., 2001. Um Discurso sobre as Ciências. Porto: Edições Afrontamento.

SCHRAIBER, L. B.; PEDUZZI, M.; SALA, A.; NEMES, M. I. B.; CASTANHERA, E. R. L. \& KON, R., 1999. Planejamento, gestão e avaliação em saúde: Identificando problemas. Ciência \& Saúde Coletiva, 4: 221-242.

SMS-RJ (Secretaria Municipal de Saúde do Rio de Janeiro) /FE-UERJ (Faculdade de Enfermagem, Universidade do Estado do Rio de Janeiro), 1998. Projeto de Implantação da Assistência de Enfermagem a Gestantes e a Parturiente na AP 3.3. Rio de Janeiro: SMS-RJ/FE-UERJ.

VALLADARES, D. P., 1999. Ações de contracepção e assistência ao parto: A experiência do Rio de Janeiro. In: Questões da Saúde Reprodutiva (K. Giffin \& S. H. Costa, org.), pp. 357-376, Rio de Janeiro: Editora Fiocruz.

van WIJK, C. M. T. G.; van VLIET, K. P. \& KOLK, A. M., 1996. Gender perspectives and quality of care: Towards appropriate and adequate health care for women. Social Science and Medicine, 43:707-720.

VEER, A. J. E. \& MEIJER, W. J., 1996. Obstetric care: Competition or co-operation. Midwifery, 12:4-10.

Recebido em 4 de outubro de 2002

Versão final reapresentada em 27 de fevereiro de 2003 Aprovado em 28 de maio de 2003 